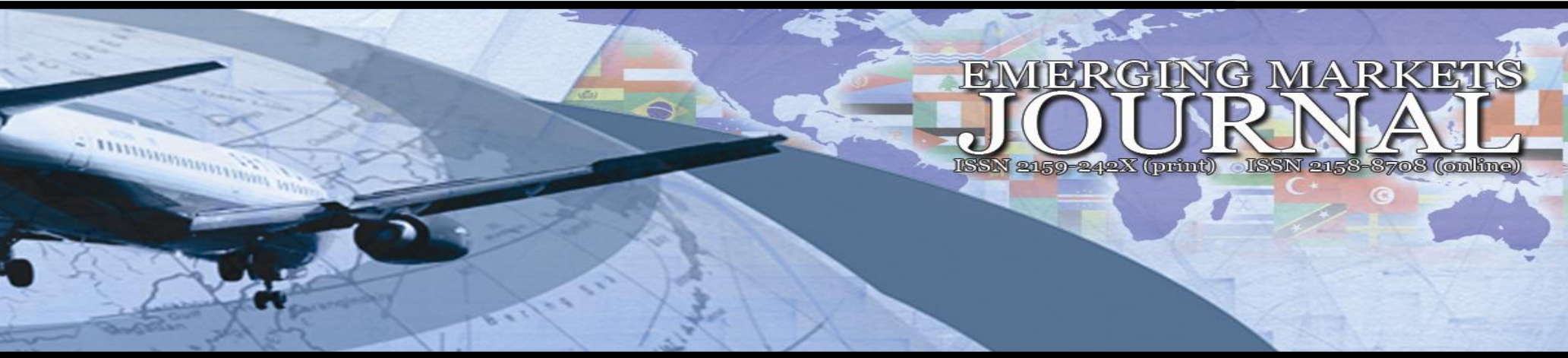

\title{
Improved Customer Churn and Retention Decision Management Using Operations Research Approach
}

\author{
Sulaimon Olanrewaju Adebiyi \\ Department of Business Administration, Fountain University \\ PMB 4491. Osogbo, Osun State. Nigeria | lanre18april@gmail.com
}

\section{Emmanuel Olateju Oyatoye}

Department of Business Administration, University of Lagos

Akoka, Lagos. Nigeria eoyatoye @ unilag.edu.ng

\section{Bilqis Bolanle Amole}

Business Administration Unit, Distance Learning Institute, University of Lagos

P. O. Box 56, Akoka, University of Lagos. Nigeria | bamole@unilag.edu.ng

Volume 6 No 2 (2016) ｜ ISSN 2158-8708 (online) ｜ DOI 10.5195/emaj.2016.101 | http://emaj.pitt.edu |

Abstract

The relevance of operations research cannot be overemphasized, as it provides the best possible results in any given circumstance, through analysis of operations and the use of scientific method. Thus, this paper explores the combination of two operations research models (analytic hierarchy process and Markov chain) for solving subscribers' churn and retention problem peculiar to most service firms. A conceptual model for unraveling the problem customer churn and retention decision management was proposed and tested with data on third level analysis of AHP for determining appropriate strategies for customer churn and retention in the Nigeria telecommunication industries. A survey was conducted with 408 subscribers; the sample for the study was selected through multi-stage sampling. Two analytical tools were proposed for the analysis of data. These include: Expert Choice/Excel Solver (using Microsoft Excel) and Windows based Quantitative System for Business (WinQSB). This paper plays important role in understanding various strategies for effective churn and retention management and the ranking of churn and retention drivers in order of importance to stakeholders decisionmaking. The study provided a framework for understanding the application of AHP and Markov chain for modeling, analysing and proffering solution to problem of churn and retention. The study recommends organizational strategies (corporate, business and functional) that reverse the churn alternatives with high priority and equally strengthen service delivery on high priority retention alternatives in order to ensure firms sustainable competitive advantage.

Keywords: AHP, Markov chain, customer churn, retention, decisions and strategies.

\section{$(c)) \mathrm{EY}$}

New articles in this journal are licensed under a Creative Commons Attribution 3.0 United States License.

\section{UILIS D-Sunt}

This journal is published by the University Library System of the University of Pittsburgh as part of its $\underline{\mathrm{D} \text {-Scribe Digital Publishing Program, and is cosponsored by the University of Pittsburgh Press. }}$ 
Improved Customer Churn and Retention Decision Management Operations Using Approach

\author{
Sulaimon Olanrewaju Adebiyi \\ Emmanuel Olateju Oyatoye \\ Bilqis Bolanle Amole
}

\section{Introduction}

In the submission of some marketing studies (Coussement, Benoit \& Van den Poel, 2010; Ngai, Xiu, \& Chau, 2009; Coussement \& Van den Poel., 2008; Berson, Simith \& Thearling, 2000), the average churn rate for mobile operators is approximately $2 \%$ per month, which means a loss of $25 \%$ of its customer base within a year. For a customer, cancellation costs are relatively small, given the fierce competition in the market, which consists of providing similar services (in terms of price and quality) and offering discounts on handsets and various other accessories. Nowadays, price is no longer a differentiator, since many telecom providers tend to equal each other's prices. The main differentiator has become the additional services. Therefore, for most of the mobile phone companies, the biggest challenge is, at the moment, switching from reactive to proactive retention; in other words, retaining customers before they take the decision to end their contract and identifying those customers with a high churn risk (Slavescu, 2011).

In order to maintain market share and profitability, telecom industries have used various approaches or management/marketing strategies to retain customers and prevent serious churn problems. Presently, most of the strategies are based on data warehousing - maintaining and managing historical and very detailed data obtained from many computing and point-of contact devices, as well as data mining techniques that enrich and transform data into meaningful information for business decisionmakers.

In this spirit, a common churn management process involves constructing a churn prediction model using past churn data, and determining key variables, which influence churn. The churn model is then used to identify and classify a list of customers with potentially high risk of churn (potential churners) from existing customer data and to perform the appropriate retention activities (Ngai, Xiu \& Chau., 2009; Coussement \& Van den Poel., 2008; Chu, Tsai \& Ho., 2007; Au, Chen \& Yao., 2003; Berson et al., 2000).

The efficiency of a company's combined CRM and churn management strategy is measured in terms of effectively decreasing of the churn rate (or increase of the retention rate), and not only by whether it can locate a list of potential churners. In the light of this, this study focuses on building operations research models in order to identify customers with a high churn risk. It deploys data from the customers themselves (demand side), rather than database (supplier point of view) which may not reflect reality on the responsiveness of the subscribers to retention strategies of the telecom industry.

This study employed the use of questionnaires and interviews to get information from subscribers \%customers' who are directly involved in the activities in the industry and therefore can provide information on what motivates their decision to churn or not to churn. Such direct information from the customers on what they desire helped to predict customer that may churn. It will also help the firms to meet the desires of profitable customers in order to retain them (retention) for the survival of the telecommunication firm.

The combination of two operations research models (Analytic Hierarchy Process and Markov chain) to the analysis of customers churn and retention decision is important in view of the some shortfalls, which is identified on Table 2.1. However, decision trees and neural networks are the staples of advanced knowledge discovery workbenches (IBM Corporation, 2010). Still, some techniques, such as neural networks, can be applied to the churn problem, that are able to uncover complex patterns as regards the types of customers and their rank, based on a score, or the possibility of churning. But, as powerful as the technique is, neural networks are difficult to interpret and do not readily give up the process by which a customer has been scored. This means that, since it does not relate with customers directly in gathering the data or getting information on the motivation for churn or retention, it will not be appropriate for better understanding of why customers churn or stay (remain) with a particular network provider, which is the thrust of this study. The reason(s) are not only customers' specific at times, but also geographical, economic, social-cultural, situational and other factors bond.

Decision trees, on the other hand, build very open and interpretable models that show the analyst the patterns discovered but fail to capture data from customers directly on reasons for churning or retaining network SIM. It is evident from Table 2.1 and the discussion that follows that this study is unique, because it proposes a combination of AHP and Markov chain not only to predict customers churn and retention in Nigeria mobile telecommunication industry, but also to unravel the motivation for churn or retain the SIM of particular network provider. This will inform good policy and strategic decisions appropriate for stakeholders in the Nigeria telecommunication industry. This will in the end engender sustainable growth of the industry, through the satisfaction of customers/subscribers demands, their profitability, as well as survival. 


\section{Literature Review}

\subsection{Social Exchange Theory}

Social exchange theory is based on the premise that human behaviour or social interaction is an exchange of activity, tangible and intangible, particularly of rewards and costs (Homans, 1961). It treats the exchange of benefits, notably giving others something more valuable to them than is costly to the giver, and vice versa, as the underlying basis of human behaviour (Homans, 1961) and therefore, a phenomenon which permeating all social life (Coleman, 1990). Not only is the market permeated by exchange, but also by the non-economic realm--the social relations situated between extremes of intimacy, self-interest or cost-benefit calculation and disinterested, as well as expressive behaviour (Blau, 1964). Social exchange is composed of actions of purposive actors that presuppose constellations of interests and resources. The complex of interdependent exchange processes constitutes the market functioning within a definite social and institutional structure, though; admittedly, the latter has not been systematically examined within rational choice theory. Since these processes are assumed to be governed by reciprocal relations-viz. Since exchange is defined as social interaction characterized by reciprocal stimuli-they would not continue in the long-run if reciprocity were violated. The concept of exchange ratio or balance-imbalance, leading to the concepts of power, dependence, and cohesion, is implied in the attribute of reciprocal reinforcements (Emerson, 1969). As a consequence, exchange theory examines the processes which establishes and sustains reciprocity in social relations, or the mutual gratifications between individuals. The basic assumption of exchange theory is that individuals establish and continue social relations on the grounds that their expectations of such relations will be mutually advantageous. The initial impetus for social interaction is provided by the exchange of benefits, intrinsic and extrinsic, independently of normative obligations (Blau, 1994).

Thus, the relationship between mobile telecommunication service providers or her agents and subscribers should be based on social exchange under ideal situation, where both parties aim at mutual advantages, but where one party gains and the other losses, this theory will be violated. Creation of customers' satisfaction has been judged as the only economic and social justification of business existence (Drucker, 1973). Therefore, telecommunication firms cannot exist profitably/survive without profitable customers that are satisfied with their relationship with organization. Thus, in order to satisfy customers, social exchange theory must hold.

\subsection{Empirical Studies on AHP, Markov Chain, Customer Churn and Retention}

Customer churning has been reported to result in the loss of businesses. This has perhaps accounted for why churn prediction has received much attention in the literature of marketing and management over the past years. In addition, it shows that a small change in the retention rate can result in significant impact on businesses (Van den Poel \& Larivie`re, 2004; Larivie`re \& Van den Poel, 2005).

Building an effective customer churn prediction model with the use of various techniques has become an issue of focus for business and academics in recent years. In order to understand how different studies have conceived their churn prediction models, this study reviews some previous studies as shown in Table 2.1.

Table 2.1: List of related literature about customer churn

\begin{tabular}{|c|c|c|}
\hline Author(s) & Data set & Method(s) \\
\hline $\begin{array}{l}\text { Wei \& Chiu, } \\
\text { (2002) }\end{array}$ & $\begin{array}{c}\text { Taiwan wireless } \\
\text { telecommunications } \\
\text { Company }\end{array}$ & $\begin{array}{l}\text { Classification } \\
\text { (decision tree) }\end{array}$ \\
\hline $\begin{array}{l}\text { Chiang, Wang, } \\
\text { Lee, \& Lin, } \\
\text { (2003) }\end{array}$ & Network banking & Association rules \\
\hline $\begin{array}{l}\text { Kim \& Yoon, } \\
\text { (2004) }\end{array}$ & $\begin{array}{l}\text { Five mobile carriers in } \\
\text { Korea }\end{array}$ & $\begin{array}{l}\text { Logistic } \\
\text { regression }\end{array}$ \\
\hline $\begin{array}{l}\text { Van den Poel } \\
\& \text { Larivie're, } \\
(2004)\end{array}$ & $\begin{array}{l}\text { European financial } \\
\text { services company }\end{array}$ & $\begin{array}{l}\text { Hazard model } \\
\text { survival analysis }\end{array}$ \\
\hline $\begin{array}{c}\text { Buckinx \& } \\
\text { Van den Poel, } \\
\text { 2005) }\end{array}$ & Retailing dataset & $\begin{array}{c}\text { Neural networks, } \\
\text { logistic } \\
\text { regression }\end{array}$ \\
\hline $\begin{array}{l}\text { Burez \& Van } \\
\text { den Poel, } \\
\text { (2007) }\end{array}$ & Pay-TV company & $\begin{array}{l}\text { Logistic } \\
\text { regression and } \\
\text { Markov chains } \\
\text { random forests }\end{array}$ \\
\hline $\begin{array}{l}\text { Hung, Yen \& } \\
\text { Wang, (2006) }\end{array}$ & $\begin{array}{l}\text { Wireless telecom } \\
\text { company }\end{array}$ & $\begin{array}{c}\text { Classification } \\
\text { (decision tree, } \\
\text { neural network) } \\
\text { clustering (K- } \\
\text { means) }\end{array}$ \\
\hline $\begin{array}{l}\text { Coussement \& } \\
\text { Van den Poel, } \\
\text { (2008) }\end{array}$ & Subscriber database & $\begin{array}{l}\text { Support vector } \\
\text { machines random } \\
\text { forests logistic } \\
\text { regression }\end{array}$ \\
\hline $\begin{array}{l}\text { Tsai \& Chen } \\
\text { (2010). }\end{array}$ & Telecommunication & $\begin{array}{c}\text { Neural networks, } \\
\text { Decisions trees, } \\
\text { association Rule } \\
\text { Apriori }\end{array}$ \\
\hline $\begin{array}{c}\text { Coussement, } \\
\text { Benoit \& Van } \\
\text { den Poel } \\
(2010) \\
\end{array}$ & Newspaper & $\begin{array}{l}\text { Neural networks, } \\
\text { Decisions trees, } \\
\text { Logistics } \\
\text { regression } \\
\end{array}$ \\
\hline $\begin{array}{c}\text { Sharma \& } \\
\text { Panigrahi } \\
(2011)\end{array}$ & $\begin{array}{l}\text { Cellular Network } \\
\text { Services }\end{array}$ & $\begin{array}{l}\text { Neural Network } \\
\text { based Approach }\end{array}$ \\
\hline $\begin{array}{c}\text { Adebiyi, } \\
\text { Oyatoye \& } \\
\text { Kuye, (2015). }\end{array}$ & $\begin{array}{c}\text { GSM subscribers } \\
\text { primary data; through } \\
\text { questionnaire FGD and } \\
\text { interview }\end{array}$ & $\begin{array}{c}\text { Analytic } \\
\text { hierarchy process } \\
\text { (AHP) }\end{array}$ \\
\hline $\begin{array}{c}\text { Adebiyi, } \\
\text { Oyatoye \& } \\
\text { Amole, (2015) }\end{array}$ & $\begin{array}{c}\text { GSM subscribers } \\
\text { primary data; through } \\
\text { questionnaire, FGD and } \\
\text { interview }\end{array}$ & $\begin{array}{c}\text { Analytic } \\
\text { hierarchy process } \\
\text { (AHP) }\end{array}$ \\
\hline $\begin{array}{c}\text { Oyatoye } \\
\text { Adebiyi \& } \\
\text { Amole, (2015) }\end{array}$ & $\begin{array}{c}\text { GSM subscribers } \\
\text { primary data; through } \\
\text { questionnaire }\end{array}$ & $\begin{array}{l}\text { Markov chain } \\
\text { analysis }\end{array}$ \\
\hline $\begin{array}{l}\text { Adebiyi, } \\
\text { Oyatoye \& } \\
\text { Mojekwu, } \\
(2015)\end{array}$ & $\begin{array}{c}\text { GSM subscribers } \\
\text { primary data; through } \\
\text { questionnaire }\end{array}$ & $\begin{array}{l}\text { Markov chain } \\
\text { analysis }\end{array}$ \\
\hline
\end{tabular}

Sources: adapted from Sharma and Panigrahi (2011); and Rodpysh, (2013).

Other scholar such as Kolajo and Adeyemo (2012) worked on data mining technique for predicting 
customers` churn behaviour in the telecommunications industry. To achieve this, they employed both descriptive model and predictive data and extracted information on the call behaviour of subscribers in order to recognize those with high probability of churn in the future. Then, the Simple K-Means and Expected Maximisation (EM) clustering algorithms were used for the clustering stage, while Decision Stump, M5P and RepTree Decision Tree algorithms were applied to the classification stage. In these, the best algorithms in both the clustering and classification stages were used for the prediction process where customers that were likely to churn were identified. The study concludes that the inability to distinguish the churner from non-churner has been the problem of telecommunications service provider. It also avers that, there are two alternatives; either to send incentives to all customers (both churners and nonchurners), which will be tantamount to a waste of money or to focus on acquisition programme (that is, acquisition of new customers) which is costlier than retention effort. Since both alternatives have negative implication on the finance of the company, distinguishing churner from non-churner is the best approach.

Moreover, the ability of the telecom service to distinguish between churner and non-churner is the central idea and the achievement of this study. Apart from the fact that most of the study employed the use of data mining which does not take into consideration the subscribers in answering questions on issues relating to his/her satisfaction in the modeling of churn and nonchurner, any study on customer churn that fails to seek the response of the subscribers/customers of the telecommunication firms may not actually capture the essence/reasons/motives of customer movement which may be far from those induced from the data mining process.

\subsection{Conceptual Framework}

Building long or short-term relationships with customers is always difficult if their needs and expectations are not understood and well met. Thus, it is a fundamental precept of modern customer management that companies should understand customers, then acquire and deploy resources to ensure their satisfaction and retention. Drucker (1973) observed that the sole purpose of every business is to "Create Customer", not lose them to other competitors. Thus, profitable customers are the essence of any business. Customers have expectations of many attributes, for instance in telecommunication industry. Such service attributes include quality of calls, coverage, SMS, Internet, bonus, tariff, customer complaint management and product quality, which were examined using conjoint analysis (Oyatoye, Adebiyi and Amole, 2013). Further, these service attributes are not likely to be of equal importance to customers' churn and retention decision. It is important to meet customer expectations on attributes that are important, if the company wants to remain in business since customers are the essence and the core the business of network providers.

This study proposed a combined application of two operations research models (AHP and Markov chain) to determine, assess, and prioritise the various service attributes as well as predict the customers churn and retention in the Nigeria telecommunication industry. The drivers of customer churn and retention were taken from both literature and preliminary interviews granted by the users/subscribers of mobile networks in Nigeria. These were presented for the respondents to make a pairwise comparison regarding the extent to which each of the driver in comparison to its pairs could motivate subscribers on churning or retention decisions. The evaluation process was able to assess if the actual service of the particular driver or attribute meets the expectation of the customer, which was used to determine customer satisfaction or dissatisfaction as the case may be. The implication of the decision taken by majority of the subscribers subsequently determines what happens to service provider/ network operators. Churn decisions will bring about less revenue, less profit and referral or bad mouth, which is the cheapest advertisement for the company with negative implication. It is the cheapest, because the companies do not pay for it, yet it affects their image and reputation and ultimately reduces its market share in the long run. On the other hand, if majority of the subscribers retain the network, it will increase revenue, and profit, reduce cost of undirected market activities, increase the market share and leads to greater referral with positive implication on the firm. A consequence of this is that subscribers who retain a network will encourage others to be on the same platform without been paid directly by the telecommunication operator to do so. From the above illustration, all the complex interaction that exists in the decision of subscribers whether to switch from their current service provider by comparing the expected future benefit against the other factors or drivers ultimately determines the industry`s performance. Thus, figure 2.1 shows the pictorial representation of the conceptual framework.

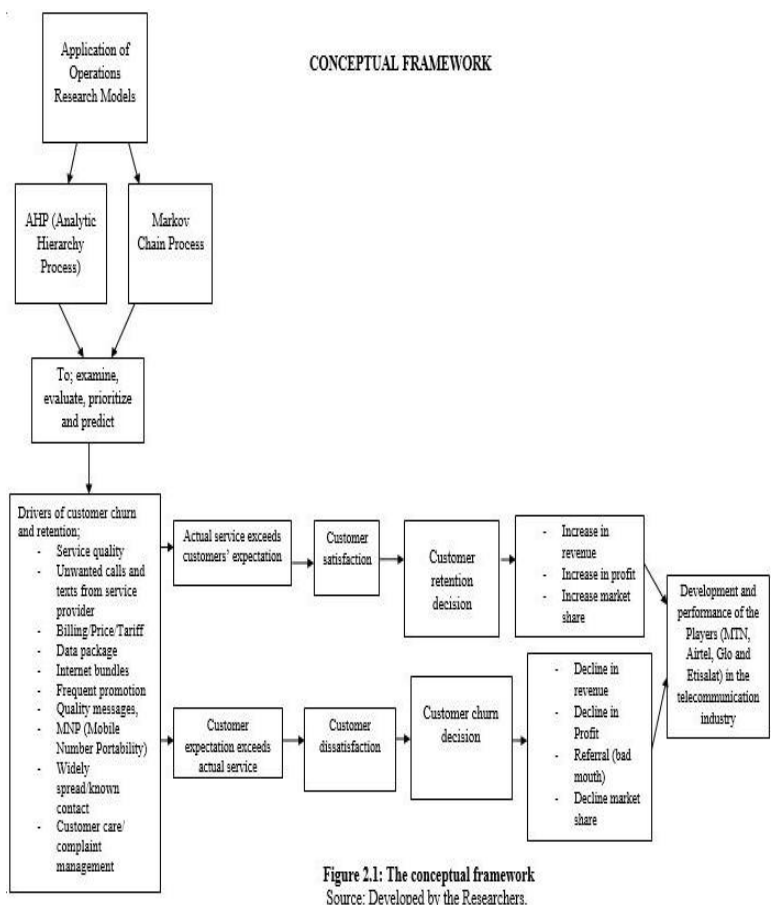

From the foregoing reviews, empirical and theoretical framework, it has been revealed that, 
customer churn and retention are rational decisions taken by subscribers/customers based on comparative/pairwise analysis of the mobile network attributes. This relates to the decision to be taken, the situation, and circumstances which surround the decision made or what may be called decision making environment.

Therefore, application of operations research methodologies of AHP and Markov chain process will assist stakeholders to make better decisions that will enhance growth and development of the service industry that experiences churn and retention problem.

\section{Research Methods}

This study aims to examine the improved customer churn and retention decision management using operations research approach. To this end, a survey was conducted with 408 subscribers who are within the campuses of six different higher institutions of learning in Lagos state, Nigeria as at the time of collecting the data. Lagos was chosen, because it is the economic nerve center of Nigeria (commercial capital), with the highest number of GSM subscribers (Adeleke and Aminu, 2012), making the largest contribution to overall economy. A decision was made to conduct a survey within campuses of tertiary institutions in order to meet large number of customers (respondents) of the four major GSM companies in the selected area which includes; MTN, Airtel, Glo, and Etisalat, who are literate and can fill the questionnaire. These operators account for over 85 percent of mobile subscriptions in the country (Pyramid Research, 2010). The sample for the study was selected through multi-stage sampling. Two analytical tools were proposed for the analysis of data. These include: Expert Choice/Excel Solver (using Microsoft Excel) and Windows based Quantitative System for Business (WinQSB). Excel Solver was used in structuring a decision into smaller parts, proceeding from the goal to objectives and from sub-objectives to the alternative courses of action. Decision-makers, then, make simple pairwise comparison judgments throughout the hierarchy to arrive at overall priorities for the alternatives. The decision problem in the study involves customer churn and drivers, factors which influence subscribers' retention and the motivation for churn and retention in the Nigeria telecommunication industry. The AHP helps people to cope with the intuitive, rational and irrational, and with risk and uncertainties in complex settings. It was used to predict likely outcomes (subscriber that are likely to churn or retain), and exercise control over changes in the decision-making system, and do cost/benefit comparisons of customer acquisition and retention.

Excel Solver is intuitive, structured in a userfriendly mode in order to be valuable for conceptual and analytical thinkers, novices, and category experts. Because the criteria are presented in a hierarchical structure, decision makers are able to specify to their level of expertise, and apply judgments, significant achievements that can help them to achieve their goals. At the end of the process, decision makers are fully cognizant of how and why decision are made, so as to achieve results which are meaningful, easy to communicate, and actionable.
Yilmaz (2009) concluded that, the main strength of the AHP is that, it is both methodologically sound and user-friendly. Its ease of use is due to a unique combination of design characteristics. The AHP frames a decision as a hierarchy, an organisational framework many people are already familiar with and easy to explain to those who are not. All inputs consist of comparisons between just two decision elements at a time; pairwise comparisons such as these are generally considered one of the best ways to elicit judgments from people (Reynolds \& Jolly, 1980). The output is easy to understand because it is based on simple scales derived from the pairwise comparisons. Finally, there is an inbuilt measure of consistency of the judgments being made which both checks the reliability of the analysis and reduces the chance of making a procedural mistake. Moreover, Windows based Quantitative System for Business (WinQSB) has 19 application modules and the user who is familiar with these models will be able to go directly to the application module and will find the use of the software self-explanatory. First order Markov chain can be employed to analyze the primary data collected from the field survey (see Adebiyi , Oyatoye \& Mojekwu, 2015) who worked on the mobile phone subscribers' preference for staying with or churning a network provider in Nigeria. The mobile network providers share data, which are are static, though they may indicate a changing picture over a time period and the exact nature of changes is known. There is a general model which assumes only one-stage dependency of the events, with each event depending on that immediately preceding it, but independent of the other prior events. In other words, subscriber choices made during the period determines the probability of choices in the forth-coming period. The events are the network services provided and the possible outcomes are the four network providers. The outcomes $X_{1}, X_{2}, \ldots, X_{n}$, are called states and the number(s) $p_{i j}$ are called the transitional probabilities.

Markov chain describes a system whose state changes over time. For example, as a system, mobile phone subscribers switch their preferences among the network operators over time. The changes are not completely predictable. It is not possible to predict accurately which network operator a particular subscriber will switch to in the next period, but rather are governed by certain probability distributions. These probability distributions incorporate a simple sort of dependence structure, where the conditional distribution of future states of the system, given some information about past states, depends only on the most recent piece of information (the decision to churn or retain a network depends on recent experience of the services received). That is, significant in predicting the future of the system is its present state, and not the path by which the system got to its present state. Markov chains illustrate many of the important ideas of stochastic processes in an elementary setting. This classical subject is still very much alive, with important developments in both theory and applications coming at an accelerated pace in recent decades. Thus, there is need for its application in modeling and predicting subscribers ' churn and retention in the growing Nigeria telecommunication industry.

Furthermore, it should be noted that the application of AHP to survey research in this study is to assist in overcoming the deficiency of traditional questionnaire 
methods. The procedure of the AHP results is not only the identification of the most important alternative, but also the preference, weight, and priority of all alternatives for each respondent. Therefore, applying AHP to survey questionnaire, elicits respondents/subscribers`opinion more precisely than that of traditional methods. This is another positive side of operations research as AHP also helps to prioritize the churn and retention drivers/factors, using a content analysis of literature and opinions of expert (customers) whose encounter the services on a daily basis. This is based on the idea that judging the relative importance of churn and retention drivers (comparing pairs of them in a hierarchical structure) is more reliable than judging their absolute importance (like in other questionnaire methods of judging items by items).

The AHP procedure involves pairwise comparisons among $\mathrm{n}$ elements in each level lead to an approximation of each $a_{i j}=w_{i} / w_{\mathrm{j}}$ which is the ratio of the weight of element $i$ to element $j$. The estimated weight vector $w$ is found by solving the following eigenvector problem: $\mathbf{A w}=\lambda_{\max } \mathrm{w}$, where the matrix $\boldsymbol{A}$ consists of $\boldsymbol{a}_{i j}$ 's, and $\lambda_{\max }$ is the principal eigenvalue of $\boldsymbol{A}$. If there is no inconsistency between a pair of elements, then $\boldsymbol{a}_{i j}$ is equal to $1 / \boldsymbol{a}_{i j}$ for any $i$ and $j$. The result is that $\lambda_{\max }=\mathrm{n}$ and we have, $\mathbf{A w}=\mathbf{n} w$, where $\mathrm{n}$ is the number of elements in each row. Written out more completely, this matrix equation takes the form:

\begin{tabular}{|c|c|c|c|c|c|c|c|}
\hline & $A_{1}$ & $A_{2}$ & . & $A_{n}$ & & & \\
\hline$A_{1}$ & $\frac{W_{1}}{W_{1}}$ & $\frac{w_{1}}{W_{2}}$ & $\cdots$ & $\frac{W_{1}}{w_{n}}$ & $w_{1}$ & & $w_{1}$ \\
\hline$A_{2}$ & $\frac{W_{2}}{W_{1}}$ & $\frac{w_{2}}{w_{2}}$ & $\cdots$ & $\frac{W_{2}}{w_{n}}$ & $w_{2}$ & $=\mathbf{n}$ & $w_{2}$ \\
\hline • & - & - & & • & - & & . \\
\hline - & - & . & & - & • & & · \\
\hline$A_{n}$ & $\frac{W_{n}}{W_{1}}$ & $\frac{\boldsymbol{W}_{n}}{\boldsymbol{W}_{2}}$ & $\cdots$ & $\frac{W_{n}}{W_{n}}$ & $w_{n}$ & & $w_{n}$ \\
\hline
\end{tabular}

Figure 1. Matrix Table

To calculate the $w$ vector (also called the eigenvector), each column of $\mathrm{A}$ is first normalized and then averaged over its rows. This vector is used to find the relative importance of each element. Observe that since small changes in $\boldsymbol{a}_{i j}$ imply a small change in $\lambda_{\max }$, the deviation of the latter from $n$ (the number of elements in a row) is a measure of consistency. The consistency ratio (CR) is given by $\left(\lambda_{\max }-1\right) /(\mathrm{n}-1)$, which is the variance of the error incurred in estimating the matrix $\boldsymbol{A}$. If the inconsistency becomes more than $10 \%$, the problems and judgments must be reinvestigated and revised (Saaty, 1980).

Among the several advantages of AHP, we can list capability of seeking consistency in judgments, being user friendly and so on. Furthermore, it affords users opportunity to structure complex problems in the form of a hierarchy or a set of integrated levels. AHP can also be combined with well-known operations research techniques to handle more difficult problems. One of the main advantages of this method is the relative ease with which it handles multiple criteria (Dura'n \& Aguilo,
2008). In addition, AHP can handle both qualitative and quantitative data effectively.

\section{Results and Discussion}

4.1. Determining appropriate retention strategies for mobile service providers in the Nigerian mobile telecommunication industry

The success or failure that an individual organization experiences, depends, to a large extent, on the ability of making acceptable decisions on time (Sharma, 2009). Thus, to arrive at such a decision, a decision maker (network provider) needs to enumerate feasible and viable courses of action (alternatives or strategies), the projection of consequences associated with each course of action and measure of effectiveness (an objective) to identify the best course of action.

Network operators need to retain customers and not lose them to competitor, since studies have shown that the acquisition of new customers generally comes at higher costs than keeping the existing customer base satisfied (Reinartz \& Kumar, 2003). Thus the knowledge of total weight (which are product of criteria vector priority and alternative vector priority), will be appropriate in formulating appropriate retention strategies for growth and survival in the industry.

\subsubsection{Computation of total weight/ global priority of each alternative for churn decision}

After the weight of elements at all level is computed, the weight of the whole level is then calculated. From the hierarchical structure of the AHP and its characteristics, it is clearly observed that each level in the hierarchy is independent of one another which implies that the probability multiplicative law holds. Hence,

probability(alternative) $=$

$\sum_{\mathrm{i}=1}^{\mathrm{n}} \operatorname{pr}$ (Desision criteria correspond to the alternative) * pr(alternative $\backslash$ corresponding Decision criterion)

Where, decision criteria and decision alternatives are independent event to one another. Owing to independent relationship that exists between criteria and alternatives in AHP, the above formula holds and the total weight is presented in table 4.1.

Table 4. 1: Customers`Churn alternatives and total weight

\begin{tabular}{|c|c|}
\hline Alternatives & $\begin{array}{c}\text { Total } \\
\text { Weight }\end{array}$ \\
\hline Frequently receiving irrelevant text & 0.1087 \\
\hline Frequently receiving irrelevant calls & 0.0251 \\
\hline Short change on service charge & 0.0851 \\
\hline Charged for services not used by operator & 0.0718 \\
\hline Easiness to port with MNP framework & 0.0606 \\
\hline Competition brought by MNP implementation & 0.0367 \\
\hline Competitors' frequent promos & 0.0491 \\
\hline Bonuses on calls/SMS/ data plan by competitors & 0.0518 \\
\hline
\end{tabular}




\begin{tabular}{|c|c|}
\hline Dubious promo of present operator & 0.0387 \\
\hline $\begin{array}{c}\text { Difficulties in making calls / sending SMS same } \\
\text { Network }\end{array}$ & 0.1330 \\
\hline $\begin{array}{c}\text { Difficulties in making calls/sending SMS to } \\
\text { another network }\end{array}$ & 0.0469 \\
\hline Insufficient data with low cost & 0.0505 \\
\hline $\begin{array}{c}\text { Sufficient data with high cost } \\
\text { Service Agent non-willing to resolve customer } \\
\text { challenges }\end{array}$ & 0.1376 \\
\hline $\begin{array}{c}\text { Service agent non-response to customer } \\
\text { complaint }\end{array}$ & 0.0523 \\
\hline Service agent being elusive & 0.0283 \\
\hline
\end{tabular}

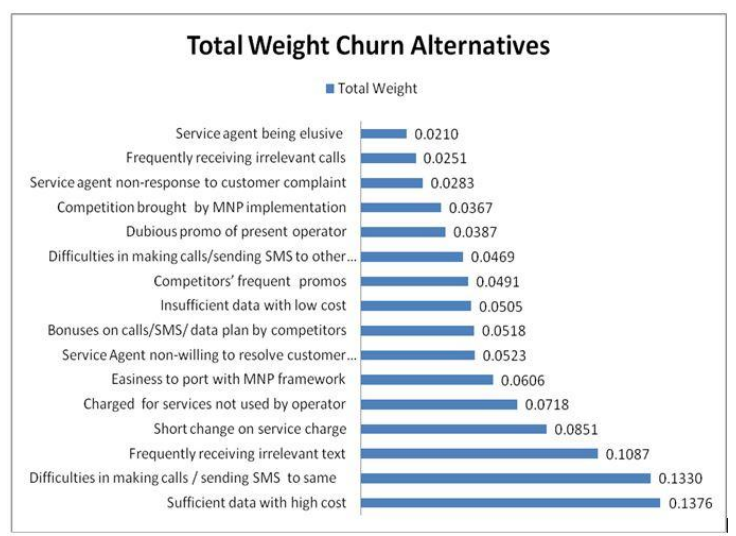

Figure 4.1. Horizontal bar chart of the total weight of customers` churn alternatives

The bar chart in figure 4.1 shows the total weight of customer churn. What motivates a customer to churn most is a network provider with high cost of data/internet plan. Even when such plan has sufficient data for the use of customer per period, with priority value $(\mathrm{pr}=0.1376)$, high cost data plan allows customers to turn to competitors. For service provider to minimize churn rate, especially for people in academic environment, there must be a sufficient data at reasonable competitive cost. Another factor that customer considered to churn from a network is difficulties in making calls or sending messages to same network. It can frustrate customers who have sufficient telecom credit and send a message either by voice or text and they are told by the network provider that their message is unable to deliver due to insufficient telecom credit. Next on the alternatives that customer considered in their churn decision is frequently receiving unsolicited irrelevant text messages from service providers. Sometimes, this may even be unbearable if customer does not have any benefit from them. In the same vein, service providers can notify customers of new service attributes which may be irrelevant to the immediate telecommunication needs of subscribers. As such, service provider should identify the communication need of different groups of subscribers in order to meet them. Other alternatives that equally drives customer churn are short-change on service charge with priority 0.0851 and this is followed by charging customer for service not used. Network operator should realize that, customers are rational human beings who consider value for money and are transitive in their comparison of what they get and what they give. Therefore, service providers should ensure fair and just billing system in order to minimize customer churn. Other factors which influence churn decision are easiness to port with MNP framework ( $\mathrm{pr}=$ 0.060), service agent non-willing to resolve customer challenges $(\mathrm{pr}=0.0523)$ and bonuses on calls/SMS/ data plan by competitors. Again as rational human being, when competitors provide similar services and give bonuses on the basic needs of effective telecommunication, which is intended to stimulate sales, customer loyalty to the present network will switch to where he/she can get more benefits. The total weight continues until the least priority of service agent being elusive with $\mathrm{pr}=0.0210$. The sum of the probabilities of the total weight equals one, thereby satisfying the law of probability.

\subsubsection{Computation of total weight of each alternative for retention decision}

After the weight of elements at all level is computed, the weight of the whole level is then calculated. From the hierarchical structure of the AHP and its characteristics, it is clearly observed that each level in the hierarchy are independent of one another, which implies that the probability multiplicative law holds. Thus,

probability(alternative)

$=\sum_{\substack{i=1 \\ *}}^{n} \operatorname{pr}($ Desision criteria correspond to the alternative)
$* \operatorname{pr}($ alternative $\backslash$ corresponding Decision criterion)

Where, decision criteria and decision alternatives are independent events to one another. Owing to independent relationship that exists between criteria and alternatives in AHP, the above formula holds and total weight for retention alternative is computed and presented in table 4.2 .

Table 4. 2: Customer retention alternatives and total weight

\begin{tabular}{|c|c|}
\hline Alternatives & Total Weight \\
\hline Call clarity & 0.1919 \\
\hline Sufficient data with low cost & 0.1496 \\
\hline Cheapness of calls & 0.1270 \\
\hline Prompt response by customer agent & 0.0821 \\
\hline Widely spread mobile number & 0.0777 \\
\hline Frequent free Internet data & 0.0666 \\
\hline Prompt delivery of complete message & 0.0663 \\
\hline Long in use number & 0.0659 \\
\hline No calls drops & 0.0343 \\
\hline Cheapness of data plan & 0.0341 \\
\hline Cheapness of Text Message & 0.0267 \\
\hline Inefficient - affordable data plan & 0.0220 \\
\hline Late delivery compete message & 0.0194 \\
\hline Late response but effective & 0.0184 \\
\hline Frequency Free Calls Services & 0.0131 \\
\hline Frequency Short Message services & 0.0131 \\
\hline Prompt delivery of incomplete message & 0.0125 \\
\hline
\end{tabular}




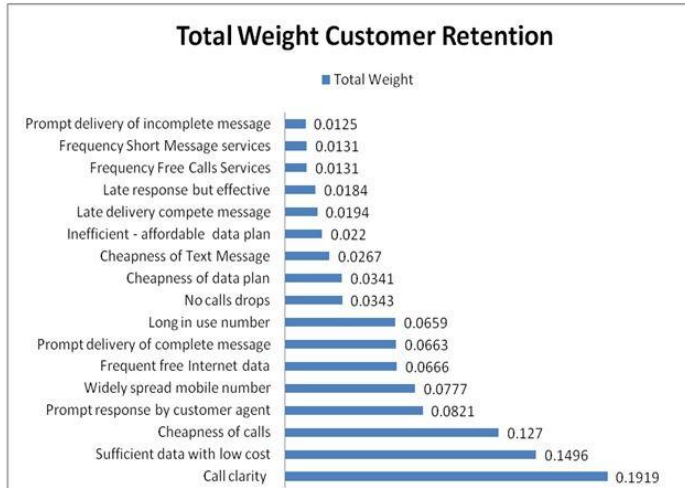

Figure 4.2. Horizontal bar chart for total weight of customers` retention alternatives

From the total weight bar chart of all the retention alternatives (figure 4.2), respondents preferred call clarity most with probability value of $\mathrm{pr}=0.1919$, out of the seventeen alternatives crucial to determining customer retention of network. It is followed by sufficient data with low cost $(\mathrm{pr}=0.1496)$, with cheap calls $(\mathrm{pr}=0.1270)$ in the third position of alternative that drive subscribers to retaining a network provider. Other alternatives and their respective probability of preference are: prompt response by customer agent in fourth position with $\mathrm{pr}=0.0821$, widely spread mobile number $(\mathrm{pr}=0.0777)$, prompt delivery of complete message with $\mathrm{pr}=0.0663$ closely and long in use number $\mathrm{pr}=0.0659$. The order continues until the least factor which drives customer's retention, which is prompt delivery of incomplete message $(\mathrm{pr}=0.0125)$. This means that the practice by which network provider delivers SMS incomplete is the least that will make customers to be loyal. The sum of the probabilities of the total weight equals to one, thereby satisfying the law of probability. Table 4.2 presents all the retention alternatives and total weight while figure 4.2 shows the bar chart presentation. Overall, the appropriate retention strategies for mobile service providers in the industry through AHP analysis are organizational strategies (corporate, business and functional) that reverse the churn alternatives with high priority and equally strengthen service delivery on high priority retention alternatives as shown in figure 4.1 and 4.2

\subsection{The use of Markov Chain analysis}

Markov chain describes a system whose state changes over time. For example, as a system, mobile phone subscribers switch their preferences among the network operators over time. The changes are not completely predictable. It is not possible to predict accurately which network operator a particular subscriber will switch to in the next period, but rather are governed by certain probability distributions. These probability distributions incorporate a simple sort of dependence structure, where the conditional distribution of future states of the system, given some information about past states, depends only on the most recent piece of information (the decision to churn or retain a network depends on recent experience of the services received). That is, significant in predicting the future of the system is its present state, and not the path by which the system got to its present state. Markov chains illustrate many of the important ideas of stochastic processes in an elementary setting. This classical subject is still very much alive, with important developments in both theory and applications coming at an accelerated pace in recent decades. Thus, there is need for its application in modeling and predicting subscribers`churn and retention in the growing Nigeria telecommunication industry.

Markov chain analysis operates under restrictive assumptions such as independence and stationarity. It is scientifically compact and easy to execute with empirical data such as survey of respondents/subscribers' that are currently using the services of network providers (see Adebiyi, Oyatoye \& Mojekwu, 2015; Oyatoye, Adebiyi \& Amole, 2015). In addition, the customer churn/retention transition probability results can serve as an indicator of the direction and magnitude of customer churn and retention process in the Nigerian telecommunication industry.

Markov model has several advantages. Firstly, it is relatively easy to derive from succession data. Secondly, the Markov model does not need deep insight into the system of dynamic change. It however, can assist in specifying areas where such insight would be important and therefore act as both a stimulant and guide for further research. Thirdly, the basic transition matrix summarizes the fundamental parameter of vibrant change in a way that is accomplished by very few other kinds of models. Lastly, the computational requirements of Markov models are self-effacing, and can easily be met by small computers package (Mubea, Ngigi \& Mundia. 2010).

\section{Conclusion and Implication for Policy}

The application of AHP to survey research in this study is to assist in overcoming the deficiency of traditional questionnaire methods. The procedure of the AHP results is not only the identification of the most important alternative, but also the preference, weight and priority of all alternatives for the subscribers. Therefore, applying AHP to survey questionnaire, elicits respondents/subscribers`opinion more precisely than that of traditional methods. This is another positive side of operations research as AHP also helps to prioritize the churn and retention drivers/factors (see, Adebiyi, Oyatoye \& Kuye, 2015; Adebiyi, Oyatoye \& Amole, 2015), using a content analysis of literature, focus group discussion (FGD) and opinions of expert (customers) whose encounter the services on a daily basis. This was based on the idea that judging the relative importance of churn and retention drivers (comparing pairs of them in a hierarchical structure) is more reliable than judging their absolute importance (like in other questionnaire methods of judging items by items). The study provided a framework for understanding the application of AHP and Markov chain for modeling, analysing and proffering solution to problem of churn and retention. Thus, managers can establish performance ranking for any service firm/industry through the combined operations research models as well as identifying the service attributes that most require improvement for sustainable development of the industry. 


\section{Recommendations for future research}

Future research could replicate this study in other service industries and different countries since this study is based on data from telecommunication industry. There is need for other study to combine the two operations models in modeling, analysing and proffering solution to problem of churn and retention in the same and other business environment. This is imperative in order to offer adequate generalization to the application of operations research models to customer churn and retention problem. Future research also should test this conceptual framework in order to contribute to new theory, whereby it can be referred by academics and practitioners.

\section{REFERENCES}

Adebiyi S. O., Oyatoye, E. O \& Kuye, O. L (2015). An analytic hierarchy process analysis: Application to subscriber retention decisions in the Nigerian mobile telecommunications industry, International Journal of Management and Economics, 48, $63-83$.

Adebiyi S. O., Oyatoye E. O \& Mojekwu, J. N. (2015). Predicting customer churn and retention rates in Nigeria's mobile telecommunication industry using Markov chain modeling, Acta Universities Sapientia Economics and Business, 3,74 - 80 .

Adebiyi S. O., Oyatoye E. O \& Amole, B. B. (2015). Determinants of customers` churn decision in the Nigeria telecommunication industry: An analytic hierarchy process approach, International Journal of Economic Behaviour, 5, 81-104.

Adeleke, A \& Aminu S. A, (2012). The determinants of customer loyalty in Nigeria's GSM market, International Journal of Business and Social Science, 3(14), 209-222.

Adeleke, A \& Aminu S. A, (2012). The determinants of customer loyalty in Nigeria's GSM market, International Journal of Business and Social Science, 3(14), 209-222.

Au, W., Chan, C. C. \& Yao, X. (2003). A novel evolutionary data mining algorithm with applications to churn prediction. IEEE transactions on evolutionary computation, 7(6), 532 545.
Berson, A., Simith S, \& Thearling, K., (2000). Building data mining applications for CRM, New York: McGraw-Hill.

Blau, P. (1994). Structural contexts of opportunities. Chicago: University of Chicago Press.

Blau, P. (1964). Exchange and power in social life. New York: John Wiley \& Sons.

Burez, J., \& Van den Poel, D. (2007). CRM at a Pay-TV company: Using analytical models to reduce customer attrition by targeted marketing for subscription services. Expert Systems with Applications, 32(2), 277 - 288.

Buckinx, W., \& Van den Poel, D. (2005). Customer base analysis: partial defection of behaviourally loyal clients in a non-contractual FMCG retail setting. European Journal of Operational Research, 164(1), 252268.

Chiang, D. A., Wang, Y. F., Lee, S. L., \& Lin, C. J. (2003). Goal-oriented sequential pattern for network banking churn analysis. Expert Systems with Applications, 25, 293 - 302.

Chu, B. H, Tsai, M. S, \& Ho, C. S., (2007). Toward a hybrid data mining model for customer retention, Knowledge Based System, 20,703-718.

Coleman, J. S. (1990). Foundations of social theory. Cambridge, Mass, Harvard University Press.

Coussement, K., \& Van den Poel, D. (2008). Churn prediction in subscription services: An application of support vector machines while comparing two parameter selection techniques. Expert Systems with Applications, 34, 313327.

Coussement, K., Benoit, D. F \& Van den Poel, D (2010). Improved marketing decision making in a customer churn prediction context using generalized additive models, Expert Systems with Applications, 37, $2132-2143$.

Dura'n, O., \& Aguilo, J. (2008). Computeraided machine-tool selection based on a fuzzy-AHP approach. Expert Systems with Applications, 34, 1787-1794. 
Drucker, P. F. (1973). Management: Tasks, Responsibilities, practices. NY: Harper \& Row.

Emerson, R. (1962). Power-Dependence relations. American Sociological Review 27, 31-41.

Homans, G. (1961). Social behaviour. New York, Harcourt, Brace \& World.

Hung, S. Y., Yen, D. C., \& Wang, H. Y. (2006). Applying data mining to telecomm churn management. Expert Systems with Applications, 31(3), 515 -524 .

IBM Corporation, (2010). Working with telecommunications, Minimizing churn in the telecommunications industry, United States of America.

Kim, H. S., \& Yoon, C. H. (2004). Determinants of subscriber churn and customer loyalty in the Korean mobile telephony market. Telecommunications Policy, 28, $751-765$.

Kolajo, T \& A. B. Adeyemo (2012). Data Mining technique for predicting telecommunications industry customer churn using both descriptive and predictive algorithms. Computing Information Systems \& Development Informatics Journal. 3(2). 27-34.

Larivie`re, B, \& Van den Poel, D. (2005). Predicting customer retention and profitability by using random forests and regression forests techniques. Expert System Application, 29(2), 472 $-484$.

Mubea, K. W, Ngigi, T. G \& Mundia, C. N. (2010). Assessing application of Markov Chain analysis in predicting land cover change: A case study of Nakuru municipality, Jomo Kenyatta University of Agriculture and Technology (JAGST), 12(2), 126-144.

Ngai, E. W. T, Xiu, L, \& Chau, D. C. K., (2009). Application of data mining techniques in customer relationship management: A literature review and classification. Expert System Application, 36, 2592-2602.
Oyatoye E. O., Adebiyi S. O and Amole, B. B. (2015). Modeling switching behaviour of Nigeria global system for mobile communication multiple SIMs subscribers` using Markov chain analysis, The Indiana University Press (IUP) Journal of Operations Management, 14(1), 7 - 31.

Oyatoye E.O, Adebiyi S.O \& Amole, B. B. (2013). An empirical study on consumers' preference for mobile telecommunication attributes in Nigeria, British Journal of Economics, Management \& Trade, 3(4), 419 - 428.

Pyramid Research (2010). The impact of mobile services in Nigeria: How mobile technologies are transforming economic and social activities; Abuja, Nigeria.

Reinartz, W.J. Kumar, V. (2003). The impact of customer relationship characteristics on profitable lifetime duration, Journal of Marketing, 67(1), 77 - 99.

Reynolds, T. \& Jolly, J. (1980). Measuring personal values: an evaluation of alternative methods. Journal Marketing Science, 17, 531-536.

Rodpysh, K. V. (2013). Applying Data Mining to customer churn analysis: a case study on the insurance industry of Iran, Open Journal of Artificial Intelligence, 1(1), 8-12.

Saaty, T. L. (1980). The Analytic Hierarchy Process, McGraw- Hill, New York.

Sharma. A \& Panigrahi, P. K. (2011). A Neural Network based approach for predicting customer churn in cellular network services, International Journal of Computer Applications, 27(11), 56-89.

Sharma J. K. (2009). Operations Research; theory and applications, third edition, Indian Macmillan Ltd.

Slăvescu E O, (2011). The implementation of uplift modeling to telecommunications marketing campaigns. The case of the Romanian mobile telecommunications market. Proceedings of The 7th International Conference Management of Technological Changes, Alexandroupolis, Greece, 2011. 
Tsai, C. F. \& Chen, M. Y. (2010). Variable selection by association rules for customer churn prediction of multimedia on demand, Expert Systems with Applications, 37, 2006 2015.

Van den Poel, D. \& Lariviere, B. (2004). Customer attrition analysis for financial services using proportional hazard models. European Journal of Operational Research, 157, 196 - 217.

Wei, C. P., \& Chiu, I. T. (2002). Turning telecommunications call details to churn prediction: A data mining approach. Expert Systems with Applications, 23, $103-112$.

Yilmaz, H. (2009). "Optimization of the product design through Quality Function Deployment (QFD) and Analytical Hierarchy Process (AHP): A case study in a ceramic washbasin", Thesis Submitted to The Graduate School of Engineering and Sciences of Izmir Institute of Technology in Partial Fulfillment of the Requirements for the Degree of Master of Science. 